\title{
Effect of vitamin d2 supplementation on serum 25 hydroxy-vitamin d3 levels: a systematic review and meta-analysis
}

\author{
C. Toyn ${ }^{1}$, A.L. Darling ${ }^{1}$, K. Hart ${ }^{1}$, L. Tripkovic ${ }^{1}$, C.P. Smith $^{2}$, J.C. Mathers ${ }^{3}$, \\ S.A. Lanham-New ${ }^{1}$ and R.M. Elliott ${ }^{1}$ \\ ${ }^{1}$ Nutritional Sciences Department, School of Biosciences and Medicine, University of Surrey, Guildford. GU2 $7 X H$, \\ ${ }^{2}$ School of Pharmacy and Biomolecular Sciences, University of Brighton, Brighton. BN2 4GJ. Sussex and \\ ${ }^{3}$ Human Nutrition Research Centre, Institute of Cellular Medicine, Newcastle University, Newcastle on Tyne, \\ NE4 5PL, UK.
}

Food manufacturers will often use vitamin $\mathrm{D}_{2}$ to fortify foods with vitamin $\mathrm{D}$, as unlike vitamin $\mathrm{D}_{3}, \mathrm{D}_{2}$ can be consumed by vegetarians and vegans ${ }^{(1)}$. However, recent research has indicated that vitamin $\mathrm{D}_{2}$ has a lesser effect on raising total vitamin $\mathrm{D}(25(\mathrm{OH}) \mathrm{D})$ status compared to vitamin $\mathrm{D}_{3}$ and could result in a decrease in $25(\mathrm{OH}) \mathrm{D}_{3}$ concentrations ${ }^{(2-4)}$. Furthermore, only vitamin $\mathrm{D}_{3}$ and not vitamin $\mathrm{D}_{2}$ has been found to decrease all-cause and cancer mortality ${ }^{(5)}$.

The objective was to conduct a systematic review and meta-analysis of randomized controlled trials (RCTs) that have supplemented with vitamin $\mathrm{D}_{2}$ via a tablet/capsule or via a food fortification vehicle, and to compare concentrations of measured serum $25(\mathrm{OH}) \mathrm{D}_{3}$ following supplementation.

A comprehensive electronic search of the EMBASE and PUBMED databases was performed, covering January 1980 to February 2017. Search terms used were as follows: "vitamin D OR 25-hydroxy* OR vitamin D2 OR vitamin D3 OR cholecalciferol OR ergocalciferol OR 25OHD” AND "supplementation" AND "randomized controlled trial OR randomized controlled trial OR RCT". Studies were also selected via online hand-searches and by examining study bibliographies. Studies were eligible if they had supplemented vitamin $\mathrm{D}_{2}$ in human adults, had a clear control/placebo comparison group and had measured serum concentration of $25(\mathrm{OH})$ $\mathrm{D}_{3}$ in both groups. Studies were then systematically reviewed for inclusion into the final meta-analysis. Out of 11 studies for systematic review, 8 study authors needed to be contacted to request missing data. Subsequently, data from 6 studies were available to be included for meta-analysis. The majority of $25(\mathrm{OH}) \mathrm{D}_{3}$ concentrations were measured in $\mathrm{nmol} / \mathrm{L}$, although one study required conversion from $\mathrm{ng} / \mathrm{mL}(1 \mathrm{ng} / \mathrm{mL}=2.5 \mathrm{nmol} / \mathrm{L})$.

A total of 803 participants were included in the 11 studies selected for systematic review. Ages ranged from 18-84 years and in the 9 studies that declared the gender of subjects, the ratio of males to females was approximately 1:3. The studies were undertaken in the UK, Ireland, USA, New Zealand, Germany and Finland and dated from 1999-2016, although all but 1 study were dated within the last 13 years. Of the 5 studies that declared ethnicity of participants, a range of Caucasian ( $n$ 343), South Asian ( $n$ 63), African-American ( $n$ 31), Hispanic ( $n$ 5), Asian ( $n$ 8) and Native American adults $(n 1)$ were included. The meta-analysis demonstrated that vitamin $\mathrm{D}_{2}$ supplementation led to a mean difference $(\mathrm{MD})$ in serum $25(\mathrm{OH}) \mathrm{D}_{3}$ as follows: $\mathrm{MD}^{\text {(fixed) }}=-11.97(95 \% \mathrm{CI}-13.93$ to $-10.1 ; \mathrm{P}<0.00001, \mathrm{p}^{\text {(heterogeneity) }}=0.36 I^{2}=9 \%$. Therefore, there was an $11.97 \mathrm{nmol} / \mathrm{L}$ drop in $25(\mathrm{OH}) \mathrm{D}_{3}$ when subjects were supplemented with vitamin $\mathrm{D}_{2}$ as opposed to a control group.

This meta-analysis indicates that overall, supplementation of vitamin $\mathrm{D}_{2}$ decreased serum $25(\mathrm{OH}) \mathrm{D}_{3}$ concentration by an average of $12 \mathrm{nmol} / \mathrm{L}$, which was highly significant $(P<0.00001)$. In addition, the findings suggest that those with higher baseline $25(\mathrm{OH}) \mathrm{D}$ concentrations may be more susceptible to the lowering effect of vitamin $\mathrm{D}_{2}$ on $25(\mathrm{OH}) \mathrm{D}_{3}$. Further research is urgently required to understand fully the molecular mechanisms underlying this drop in $25(\mathrm{OH}) \mathrm{D}_{3}$ levels, as well as the long-term implications of vitamin $\mathrm{D}_{2}$ supplementation on health outcomes and mortality.

1) Arya. (2012) Aust Fam Physician. 41(5):73-93.

2) Lehmann et al. (2013) The Journal of Clinical Endocrinology \& Metabolism. 98(11):4339-4345.

3) Logan et al. (2013) Br J Nutr. 109(6):1082-1088.

4) Itkonen et al. (2016) Br J Nutr. 115(7):1232-1239.

5) Bjelakovic et al. (2011) Cochrane Database Syst Rev (7):CD007470. 